\title{
What Are the Potential Factors That Will Affect the Value of Bitcoin in the U.S.?
}

\author{
Kaibing Yang ${ }^{1, \dagger}$, and Ziyan Zhang ${ }^{2, *,}$ \\ ${ }^{1}$ Economics, College of Liberal Arts \& Sciences, University of Illinois at Urbana-Champaign, Urbana, IL, United \\ States, kaibing2@illinois.edu \\ ${ }^{2}$ Economics, Krannert Management School, Purdue University-West Lafayette, West Lafayette, IN, United States, \\ zhan4143@purdue.edu \\ * Corresponding author: guanghua.ren@gecacademy.cn \\ These authors contributed equally.
}

\begin{abstract}
As a representation of Cryptocurrency, Bitcoin may have the potential to become a reliable currency due to its characteristics of decentralization and built-in scarcity. The evolution of Bitcoin shows some similarities with gold, that is an inflation hedge with a stable price. The purpose of this study was to determine what factors might affect the value of Bitcoin, which cause it eventually circulate with a stabilized price and become a future gold-like commodity under a macroeconomic scope. This paper conducted a generalized linear regression analysis of the Bitcoin price and gold price on the inflation rate, interest rate, and current account by using RStudio. Based on the United States annual data, this paper found evidence that the U.S. inflation rate, U.S. interest rate, and U.S. current account did not have significant effects on the gold price. However, the Bitcoin price was significantly affected by the U.S. inflation rate and U.S. interest rate. This implied that Bitcoin was not as stable as gold at current stage, but one possible speculation is that Bitcoin has the potential to counter inflation in the future.
\end{abstract}

Keywords: Bitcoin.

\section{INTRODUCTION}

\subsection{Bitcoin}

Cryptocurrency, also called crypto, was first brought up in the late 20th century. Like the paper currency or digital currency in each country, cryptocurrency is a digital asset that works as a medium of exchange. However, instead of being monitored and centralized by the bank, government, or any central authority, it uses decentralized control where each coin will be stored in a ledger that uses cryptography to secure the ownership and transaction. Cryptocurrency has emerged as a new type of currency in the U.S. since the last decade. The value of Bitcoin, as the most known cryptocurrency, has risen from approximately 120 United States Dollar in 2013 to around 57,000 United States Dollar in 2021 since it first came out. In the first several years of its existence, there have been studies that tried to validate the probability of cryptocurrency becoming a new reliable commodity for exchange.
Unlike other currencies, Bitcoin's built-in scarcity is what makes it different from other cryptocurrencies and traditional currencies. Traditional currencies can be printed out by the government and will create unlimited new units. Similarly, Dogecoins, one of the alternatives of Bitcoin, also have unlimited units. However, the total unit of Bitcoin is fixed at 21 million units, making Bitcoin to be similar to gold. This idea was introduced by an unknown person online with username of Satoshi Nakamoto in 2008. He used the Secure Hash Algorithm 2 , more specifically, SHA-256 cryptographic function as its proof-of-work scheme. The process of decrypting the function was called mining. When Bitcoin first came out, for every successful verification of a block, the miner would be rewarded with 50 Bitcoins, and after every 4 years, the amount of reward would be halved. With this pattern, the total amount of Bitcoin would be 21 million.

Other than the built-in scarcity, Bitcoin still has more advantages. Similar to some other cryptocurrencies, the deposit and transaction are more convenient and safer, with better privacy. With its virtuality and the direct online transaction, it prevents the danger of being lost 
during the transaction, thus eliminates the need for a third party to interfere, which leads to lowering the transaction and deposit fee. All things have two sides, including the anonymous characteristic of Bitcoin. Because of its privacy, it is hard to trace and regulate all the transactions, which makes the governments harder to trace the money when dealing with money laundering.

\subsection{Gold}

As a natural resource physically difficult to replicate or synthesize, gold has been regarded as one of the most important precious metals. Tully and Lucey (2007) noted that gold had acted as a multifaceted metal down through the centuries. Although gold is an industrial metal, only approximately $10 \%$ of gold demand is derived from industry and it is widely used as an investible metal. Gold acts as a commodity and a monetary asset, possessing similar characteristics to money [1]. As a precious metal, gold can be transacted anytime within a day, which makes the market for gold presents exceptional liquidity. The high liquidity of gold was indicated by Hillier et al., who also claimed gold was a primary form of reserve asset held by central banks around the globe [2]. In the U.S., gold was discovered around 1848 in California, and since then the gold rush has begun, but its standard price related to the U.S. dollar in the Federal Reserve was not introduced until 1913. The gold price was extremely low in the first several decades of existence because of its novelty. From the 1970 s to the 1990 s, the gold price was extremely unstable, and its high volatility lasted for half a century. As the readily recoverable gold reserves dwindle in stable places, people start to recognize that the supply constraint of gold makes it a great hedge against inflation. Around the year 2000, the trend of the gold price was able to stabilize, albeit with some fluctuations.

\subsection{Comparison}

Table 1. Properties of Bitcoin and Gold

\begin{tabular}{|c|c|c|}
\hline Structure & Bitcoin & Gold \\
\hline $\begin{array}{c}\text { Reason of } \\
\text { Scarcity }\end{array}$ & $\begin{array}{c}\text { Limited by the } \\
\text { total amount }\end{array}$ & $\begin{array}{c}\text { Decentralized } \\
\text { Mechanicand } \\
\text { Limitations }\end{array}$ \\
\hline $\begin{array}{c}\text { Way of } \\
\text { Discovery }\end{array}$ & Mining & Mining \\
\hline $\begin{array}{c}\text { Way of } \\
\text { Deposit }\end{array}$ & $\begin{array}{c}\text { Virtual Wallet } \\
\text { with Passcode }\end{array}$ & Deposit in Bank \\
\hline $\begin{array}{c}\text { Way of } \\
\text { Transaction }\end{array}$ & $\begin{array}{c}\text { Online } \\
\text { Transaction }\end{array}$ & $\begin{array}{c}\text { Physical } \\
\text { Transaction }\end{array}$ \\
\hline $\begin{array}{c}\text { Transaction } \\
\text { Privacy }\end{array}$ & Anonymous & $\begin{array}{c}\text { Proof of Identity } \\
\text { with Confidentiality }\end{array}$ \\
\hline Deposit Fee & Free & $\begin{array}{c}\text { Up to 1\% of } \\
\text { Deposit Fee }\end{array}$ \\
\hline
\end{tabular}

In order to become a stable and reliable currency in the U.S., Bitcoin may have some similar macroeconomic characteristics to gold. Table 1 showed a summary of different properties of both Bitcoin and Gold. Both Bitcoin and gold were discovered through mining. The former one is the process of decrypting the function while the latter one is physical mining. One additional similarity is that both commodities are decentralized, however, Bitcoin has some properties that seem to be better than gold. Its characteristics of virtuality, anonymity and free of deposit make it have a higher potential to become a more stable commodity of exchange.

\subsection{Research Question}

There has been little previous evidence that examined macroeconomic factors that will affect Bitcoin price. Therefore, this study tried to give a preliminary result to see what may cause the change in the value of Bitcoin in the U.S. and compared it with gold under a macroeconomic scope.

\section{LITERATURE REVIEW}

There is a major contradiction on whether Bitcoin or any cryptocurrency is reliable and stable enough to become a new currency. Most of the studies gave predictions and showed that Bitcoin as a cryptocurrency does have the potential to become a more reliable currency for payments by using empirical evidence and comparison [3, 4]. Harwick also stated that cryptocurrency does have the qualities of a useful commodity for exchange and compared it with gold [5].

However, the volatility was a major concern that made most of the countries prohibited any transaction with Bitcoin. Despite the early studies, there has been little research on the relationship between the factors and the price of the cryptocurrency. Katsiampa compared a variety of generalized autoregressive conditional heteroskedasticity models, also called GARCH models to try to estimate the volatility of Bitcoin and found that the AR-CGARCH model is the best fit and gave the result that the market of Bitcoin is highly speculative [6]. The GARCH models are models that can predict volatility in financial markets. Later, Sovbetov (2018) followed his path and used the Autoregressive Distributed Lag, ARDL technique to examine some internal factors (total market prices, trading volume, and volatility) that influence the prices of several cryptocurrencies [7]. The ARDL technique is used to predict the current values of a dependent variable based on both the current values of an explanatory variable and the lagged, or so-called past period values of this explanatory variable.

One problem with the early studies on the prices of Bitcoin is that there is barely enough data to set up the model to predict the evolution of Bitcoin from the stances of macroeconomics. Nevertheless, combining the findings from Harwick and the U.S. market price data of the Bitcoin, Iwamura was able to find that inflation somehow does affect the cryptocurrency but acts differently as inflation affects gold [5-8]. As a young and 
evolving type of currency, there is not enough research about the relationship between certain factors and the value of the cryptocurrency. The objective of this study is to investigate the effects of macro-variables on the prices of Bitcoin by using a multivariable linear regression model.

As Harwickproved that cryptocurrency does have the qualities of a useful commodity for exchange, this paper assumed that Bitcoin can become a new currency in the U.S [5]. Taking account of Sovbetov's idea and combining with the finding of Iwamura, since inflation rate (inflation), current account balance (current account), and interest rate (interest) are all factors that will affect the value of a currency, one additional hypothesis was that Bitcoin may also be affected by these variables [7, $8]$.

\section{METHODOLOGY}

\subsection{Assumption}

As substitutes, since inflation will cause the U.S. dollar to depreciate, it is expected that there would be a positive effect between the U.S. inflation rate and the value of Bitcoin. Similarly, having a current account deficit will lead to the depreciation of the U.S. dollar, there would be a negative effect between the percentage change in the current account and the value of Bitcoin. Also, an increase in the interest rate will lead to an appreciation of the U.S. dollar, hence there would be a negative effect between the U.S. interest rate and the price of Bitcoin.

\subsection{Data Source}

The data of the price of the Bitcoin was pulled from CoinDesk (www.coindesk.com/price/bitcoin), the gold price was pulled from GoldHub (www.gold.org/goldhub/data/gold-prices), and the U.S. inflation rate, U.S. interest rate, and current account balance were collected from World Bank Open Data (data.worldbank.org). Since the price of Bitcoin was firstly released in 2013 and the data of inflation rate, interest rate, and current account balance have been announced annually until 2019 , the sample was restricted within the year from 2013 to 2019 . The annual prices of Bitcoin were calculated by taking the average daily Bitcoin price in each year. The annual gold price was calculated in a similar way.

\subsection{Model}

With the limited research that used quantitative evidence in recent years, there has been no quantitative model investigating the effect of macroeconomic factors on the price of Bitcoin. Thus, this paper started from the basic linear regression.

$\ln \left(Y_{T, 1}\right)=\beta_{0}+\beta_{1} x_{T, 1}+\beta_{2} \ln \left(x_{T, 2}\right)+\beta_{3} x_{T, 3}+\mu_{\mathrm{i}}$

where $Y_{T}$ is the value of the Bitcoin in year $T, x_{T, 1}$ is the U.S. inflation rate in year $T, \ln \left(x_{T, 2}\right)$ is the percentage change in U.S. Current Account in year $T, x_{T, 3}$ is the U.S. interest rate in year $T$, and $\mu_{\mathrm{i}}$ is the error term. The same regression model.

$$
\ln \left(Y_{\mathrm{T}, 2}\right)=\beta_{0}+\beta_{1} x_{\mathrm{T}, 1}+\beta_{2} \ln \left(x_{\mathrm{T}, 2}\right)+\beta_{3} x_{\mathrm{T}, 3}+\mu_{\mathrm{i}}
$$

where the gold price in year $T$ as $Y_{T, 2}$ was also used to compare its coefficients with the Bitcoin's coefficients.

\section{RESULT}

In Table 2, the prediction of the change in Bitcoin price per year considered three independent variables: the change in U.S. inflation rate per year is denoted as inflation, a current account is defined as the percentage change in the U.S. current account every year, and the percentage change in U.S. interest rate in each year is represented by interest. $\mathrm{P}$-value $(\operatorname{Pr}(>|t|))$ determines if the three independent variables are correlated with the dependent variable. The standard is set at 0.05 , or $5 \%$ as the rejection region, which means if the $\mathrm{P}$-value is greater than 0.05 , this value is not significant. Thus, there is insufficient evidence to conclude that the two variables are correlated. Namely, the independent variable has no significant effect on the dependent variable. If the $\mathrm{P}$ value is less than 0.05 , then there is a correlation between the change in Bitcoin price and the dependent variable.

Table 2. Linear Regression on Bitcoin price of inflation, currenaccount and interest

\begin{tabular}{|c|c|c|c|c|c|c|c|}
\hline Residuals: & $\begin{array}{r}1 \\
-0.3653\end{array}$ & $\begin{array}{r}2 \\
-0.03977\end{array}$ & $\begin{array}{r}3 \\
-0.08029\end{array}$ & $\begin{array}{r}4 \\
0.14759\end{array}$ & $\begin{array}{r}5 \\
0.59585\end{array}$ & $\begin{array}{r}6 \\
0.04907\end{array}$ & $\begin{array}{r}7 \\
-0.30715\end{array}$ \\
\hline \multicolumn{8}{|l|}{ Coefficients: } \\
\hline & & Estimate & Std. Error & t value & $\operatorname{Pr}(>|t|)$ & & \\
\hline (Intercept) & & 0.4602 & 0.9644 & 0.477 & 0.6659 & & \\
\hline inflation & & 2.1713 & 0.3831 & 5.667 & 0.0109 & * & \\
\hline currentaccount & & -1.1567 & 1.4757 & -0.784 & 0.4903 & & \\
\hline interest & & 1.4078 & 0.3062 & 4.597 & 0.0193 & * & \\
\hline
\end{tabular}

* Significant at the 0.05 probability level.

** Significant at the $\mathbf{0 . 0 1}$ probability level.

Residual standard error: $\mathbf{0 . 4 5 2 8}$ on 3 degrees of freedom 
Multiple R-squared: 0.9496

F-statistic: 18.85 on 3 and 3 DF, p-value: 0.01891

Table 2 presented that inflation $(\mathrm{P}=0.0109)$ and interest $(\mathrm{P}=0.0193)$ both had a $\mathrm{P}$-value that was less than 0.05 and the current account's P-value was 0.4903, which was much greater than 0.05 . Therefore, the U.S. inflation rate and U.S. interest rate had a significant effect on the price of Bitcoin while the effect of current account balance change on the price of Bitcoin was not significant. More specifically, for every percentage increase in the U.S. inflation rate, the price of Bitcoin would increase by 2.1713 percent and for every percentage increase in the U.S. interest rate, the Bitcoin price would increase by 1.4078 percent. Both variables had a positive effect on the change in Bitcoin price. This implies that the U.S. inflation rate has a larger effect on the price of Bitcoin than the U.S. interest rate. The Rsquared value of the model was 0.9496 and the adjusted $\mathrm{R}$-squared value was 0.8992 , both were greater than 0.8 , the prediction was well-fitted from the result.

In Table 3, the same independent variables and linear regression model were used to try to predict the change in gold price every year. However, inflation $(P=0.116)$, current account $(P=0.105)$ and interest $(P=0.296)$ all had a P-value that was greater than 0.05 . This result showed that the U.S. inflation rate, U.S. current account balance, and U.S. interest rate all did not have any significant effect on the gold price. Also, the value of Rsquared (0.7298) and adjusted R-squared (0.4596) proved that this model was not well-fitted since less than $75 \%$ of the predictions are correct.
Adjusted R-squared: 0.8992

\section{DISCUSSION}

The finding proved that the U.S. inflation rate and the interest rate would affect the price of Bitcoin but the current account balance showed an insignificant effect on the Bitcoin price in the U.S. This implies that Bitcoin in some way can be a substitute for the dollar in the U.S. It also proved Luther (2013, 2014), Olson (2013), and White (2014)'s findings that Bitcoin did have the potential to become a more reliable and useful currency.

However, contrary to the findings of Harwick (2016), with the same variables, there was inadequate evidence to support the significant effect of the U.S. inflation rate, current account, and the interest rate on the gold price. It is worth discussing the results revealed in the findings. One possible reason is that this may be due to the fact that Bitcoin is still new and evolving, its volatility is unstable while the gold price has remained at a stable stage since around 2005, as in Figure 1 from Macrotrends gold price (https://www.macrotrends.net/1333/historical-goldprices-100-year-chart). Compared the Bitcoin price shown in Figure 2 with the gold price before its stable stage in figure 2, similar to the Bitcoin price, when gold was first found, it also has high volatility for the first several decades. From this standpoint, Bitcoin could be considered as a potential hedge against inflation and a future gold-like commodity since the price of Bitcoin has followed a similar pattern with the gold price. Bitcoin may also become an inflation hedge and may not be affected by the change in the current account and interest rate in the future.

Table 3. Linear Regression on Gold price of inflation, currenaccount and interest

\begin{tabular}{|c|c|c|c|c|c|c|}
\hline \multicolumn{7}{|l|}{ Residuals: } \\
\hline 1 & 2 & 3 & 4 & 5 & 6 & 7 \\
\hline 0.026889 & 0.025940 & -0.014435 & 0.003156 & -0.066416 & -0.013333 & 0.038199 \\
\hline \multicolumn{7}{|l|}{ Coefficients: } \\
\hline & Estimate & Std. Error & t value & $\operatorname{Pr}(>|t|)$ & & \\
\hline (Intercept) & 6.91145 & 0.10764 & 64.206 & 8.32E-06 & $\star * *$ & \\
\hline inflation & 0.09361 & 0.04276 & 2.189 & 0.116 & & \\
\hline currentaccount & -0.37876 & 0.16472 & -2.300 & 0.105 & & \\
\hline interest & 0.04320 & 0.03418 & 1.264 & 0.296 & & \\
\hline
\end{tabular}

* Significant at the 0.05 probability level.

** Significant at the 0.01 probability level.

*** Significant at the 0.001 probability level.

Residual standard error: 0.05054 on 3 degrees of freedom

Multiple R-squared: 0.7298

Adjusted R-squared: $\mathbf{0 . 4 5 9 6}$ 


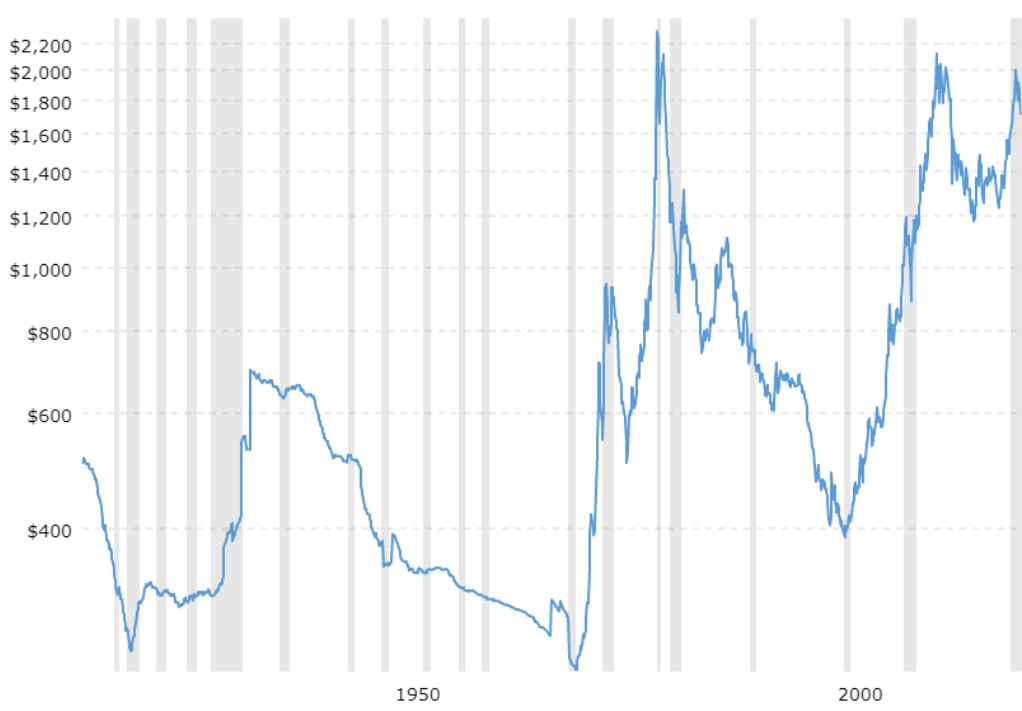

Fig. 1. Gold Price since 1915

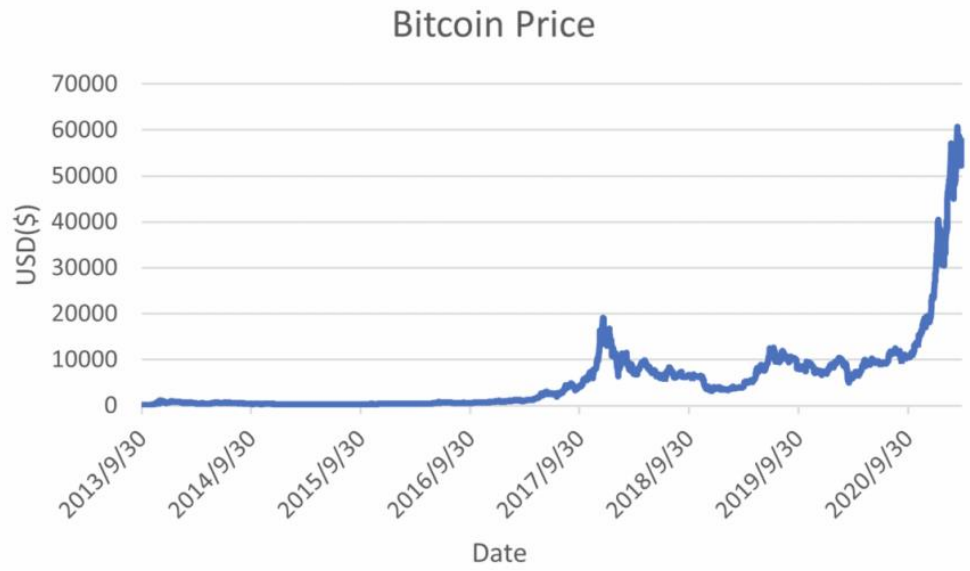

Fig. 2. Bitcoin Price since 2013

\section{CONCLUSION}

This study used a generalized linear regression model with U.S. inflation rate, U.S. current account balance, and U.S. interest rate as variables to predict their effects on the price of Bitcoin and gold. This study provided a preliminary result of how the value of Bitcoin and gold would change and the analysis from the regression model showed that the U.S. inflation rate and interest rate both had a positive effect on Bitcoin price but none of these three variables had significant effect on the gold price. This result indicated that gold is a stable commodity for exchange against inflation, change in the current account, and interest rate. For Bitcoin, it would take a longer period of time to notice the similar properties from the stances of macroeconomics as gold.

However, this paper had some limitations. One was that there might be more factors that were not accounted for but would also affect the value of Bitcoin. Also, cryptocurrency was invented recently, only a few researchers had used models to predict because of its value novelty, obscurity, and intangibility. There may be a better regression model that can give a better fit of the prediction model with a better significance if more data points are collected. In addition, the latest data was collected at the end of the year 2019, which was before the COVID-19 pandemic, this might introduce a new potential variable to the model that should be considered in future studies.

\section{REFERENCES}

[1] Tully, Edel, and Brian M. Lucey. "A Power GARCH Examination Of The Gold Market". Research In International Business And Finance, 21, 2 (2007).

[2] Hillier, David et al. "Do Precious Metals Shine? An Investment Perspective". Financial Analysts Journal, 62, 2 (2006). 
[3] Luther, William J., and Josiah Olson. "Bitcoin Is Memory”. Journal Of Prices \& Markets, 3, 3 (2013).

[4] Luther, William J., and Lawrence H. White. "Can Bitcoin Become A Major Currency?". SSRN Electronic Journal, (2014).

[5] Harwick, Cameron. "Cryptocurrency and the Problem of Intermediation." The Independent Review, 20, 4 (2016).

[6] Katsiampa, Paraskevi. "Volatility Estimation For Bitcoin: A Comparison Of GARCH Models". Economics Letters, 158 (2017).
[7] Sovbetov, Yhlas. "Factors Influencing Cryptocurrency Prices: Evidence from Bitcoin, Ethereum, Dash, Litcoin, and Monero.” Journal of Economics and Financial Analysis, 2, 2 (2018).

[8] Iwamura, Mitsuru, et al. "Can We Stabilize the Price of a Cryptocurrency? Understanding the Design of Bitcoin and Its Potential to Compete with Central Bank Money." Hitotsubashi Journal of Economics, 60, 1 (2019). 